\title{
BMJ Open Sociodemographic, home environment and parental influences on total and device-specific screen viewing in children aged 2 years and below: an observational study
}

\author{
Si Ning Goh, ${ }^{1}$ Long Hua Teh, ${ }^{1}$ Wei Rong Tay, ${ }^{1}$ Saradha Anantharaman, ${ }^{1}$ \\ Rob M van Dam, ${ }^{1,2,3}$ Chuen Seng Tan, ${ }^{2}$ Hwee Ling Chua, ${ }^{4}$ Pey Gein Wong, ${ }^{4}$ \\ Falk Müller-Riemenschneider ${ }^{2,5}$
}

To cite: Goh SN, Teh LH, Tay WR, et al.

Sociodemographic, home environment and parental influences on total and device-specific screen viewing in children aged 2 years and below: an observational study. BMJ Open 2016;6:e009113. doi:10.1136/bmjopen-2015009113

- Prepublication history for this paper is available online To view these files please visit the journal online (http://dx.doi.org/10.1136/ bmjopen-2015-009113).

SNG and LHT contributed equally.

Received 17 June 2015 Revised 7 October 2015 Accepted 2 November 2015

\section{CrossMark}

For numbered affiliations see end of article.

\section{Correspondence to}

Dr Falk Mueller-

Riemenschneider; falk. mueller-riemenshneider@ nuhs.edu.sg

\section{ABSTRACT}

Objective: This study aimed to investigate total and device-specific screen viewing (SV) and its determinants in children aged 2 years and below. Design: Cross-sectional study conducted in February 2014.

Setting: Well-child clinics in Singapore national polyclinics.

Participants: Parents of children (Singapore citizens or permanent residents) aged 2 years and below were enrolled during routine clinic visits. Out of 794 eligible parent-child dyads, $725(91.3 \%)$ provided informed consent and were included in the analysis.

Main outcome measures: Device-specific information on SV and determinants was ascertained using interviewer-administered survey questionnaires. The prevalence and duration of aggregate and devicespecific SV were reported. Associations with potential determinants were investigated using multiple logistic regression analysis. A p value less than 0.05 was considered statistically significant.

Results: The prevalence of daily SV and SV $\geq 2 \mathrm{~h} /$ day constituted $53.5 \%$ and $16.3 \%$, respectively. The majority of children aged 18-24 months (88.2\%) engaged in daily SV. TVs and mobile devices were the most commonly used screen devices, followed by computers and video consoles. In multivariable analysis, younger child age, Chinese ethnicity and setting rules on time of SV were strongly and consistently associated with lower levels of any SV and SV $\geq 2 \mathrm{~h} /$ day. Parental knowledge of SV recommendations and less parental SV were additionally associated with lower levels of $S V \geq 2 \mathrm{~h} /$ day. The number of screen devices was not associated with children's SV.

Conclusions: In contrast to recommendations, SV prevalence in children aged less than 2 years is high and appears to increase steadily across age groups. TVs and mobile devices are most frequently used. Improving parental knowledge of SV recommendations, reducing parental SV and especially the implementation of strict rules on SV

\section{Strengths and limitations of this study}

- This study investigates screen viewing in very young children considering television viewing, as well as other relevant up-to-date screen device types, such as computers, game consoles and mobile devices.

- The study comprehensively assesses sociodemographic, parental and home environmental influences on screen viewing.

- Our findings are based on a large multiethnic Asian population with a very high response rate.

- The study provides evidence that is highly applicable to the development of early childhood interventions aimed at reducing screen viewing.

- The main limitation is the fact that screen viewing as the main outcome was based on a proxy report and could not be determined objectively.

time could be successful strategies to reduce SV in young children.

\section{BACKGROUND}

Screen viewing (SV) has been associated with substantial detrimental health effects, including a higher risk of type 2 diabetes mellitus, cardiovascular diseases and premature mortality. ${ }^{1}{ }^{2}$ In children, increases in the time spent on SV have been found to negatively affect cognitive and language development, ${ }^{3}{ }^{4}$ social interaction, ${ }^{56}{ }^{6}$ attention deficits, ${ }^{4} 78$ as well as behavioural problems. ${ }^{9-11}$ SV in children has also been linked to obesity, ${ }^{12}$ metabolic risk and impaired vision. ${ }^{13-15}$

For children above the age of 2 years, $\mathrm{SV}$ recommendations, for instance from 
the American Academy of Pediatrics, state not to engage in more than $2 \mathrm{~h}$ of television (TV) or screen time per day. ${ }^{16}$ However, recent evidence-based recommendations for very young children (here defined as children below the age of 2 years) have discouraged SV altogether. ${ }^{17}{ }^{18}$ Despite these recommendations, the use of screen devices in young children seems to have become common practice in recent years. For instance, in Japan, $86 \%$ of children spend over $1 \mathrm{~h}$ of TV time a day by 18 months of age. ${ }^{19}$ In Australia, the average child between 0 and 4 years spends $2.5 \mathrm{~h}$ on $\mathrm{TV}^{20}$ per day. Similarly, in the USA, $90 \%$ of children regularly watch TV or videos by age 2 , with the average duration exceeding $1.5 \mathrm{~h}$ a day. 2122

Such sedentary behaviours have been shown to persist across age, indicating that children who spent more time watching TV, watch more TV later in life and that these early life behaviours could be associated with adverse health consequences, such as increased body mass index and serum cholesterol levels, as well as decreased cardiorespiratory fitness later in life. ${ }^{23-26}$ The increasing amount of time children spent on SV and the potential long-term implications of SV highlight the public health importance of preventing the adoption of SV behaviours early in life.

With technological advancements, screen devices have become pervasive in everyday life. Nowadays, comprehensive assessments of SV patterns in children have to consider TV, computer and video consoles, as well as mobile screen devices, especially smartphones and tablets. ${ }^{16}$ Their portability and ease of use anywhere and anytime could have important implications on the way these screen devices are being used. Studies in older children and adolescents have already highlighted their widespread use. ${ }^{27} 28$ However, little is known about current SV patterns in young children, especially with regard to the use of different screen devices, ${ }^{29}{ }^{30}$ despite the common perception that modern mobile screen devices are more interactive and possibly beneficial for children's health. According to a recent systematic review of the available evidence in children aged 3 years and below, the majority of studies reported TV and video viewing. Only five studies have reported computer use and no studies have explored mobile device use. ${ }^{31}$ Equally important, little is known about the time when children begin to be exposed to these devices on a regular basis, their sociodemographic profile and potentially modifiable determinants. This knowledge is important to understand when and how best to prevent excessive SV behaviour in children, as well as later in life.

This study aimed to investigate overall and devicespecific SV patterns in children aged 2 years and below. It also investigated differences in SV behaviour across age, sociodemographic factors, screen home environment, as well as parental knowledge and practice-related determinants of early childhood SV.

\section{METHODOLOGY}

\section{Participants and procedures}

This was a cross-sectional study conducted in February 2014 among parents bringing their healthy children, aged 2 years and below, to two National Healthcare Group Polyclinics (Singapore has a total of 18 polyclinics) for their well-child health visits, which may include developmental assessment and/or vaccinations. The take-up rate of this programme for children up to 2 years is more than $97 \%$, providing a good representation of the children in the region at a given point in time. ${ }^{32}$ Parents satisfying the eligibility criteria were invited to participate in the study. Participants who were not Singapore citizens were excluded and verbal consent from the participants was obtained. After consent was obtained, trained interviewers administered survey questionnaires in a standardised form in the participants' preferred language (English, Chinese, Malay and Tamil) during clinic visits.

This study was approved by the Singapore National Health Care Group Domain Specific Review Boards (DSRBs). Participation was entirely voluntary and informed consent was received from all the parents or caregivers.

\section{Measurements}

The study questionnaire was developed following a comprehensive literature review and refined through pilot studies. Interviewers were trained to ensure consistent administration of the survey questionnaires.

\section{SV behaviour}

Parents were asked to provide information about the amount of screen time their child was exposed to during weekdays and weekends. Parental recall of their child's SV time has been shown to be reliable, correlating well within previous observational studies. ${ }^{33}$ SV behaviour was ascertained in four broad device categories: TV/ digital video disc, computer, video game consoles and mobile devices (including smartphones, tablets and other portable devices). To determine total SV, the amount of time spent on individual device categories was added up for weekdays and weekends with weights corresponding to $5 / 7$ and $2 / 7$, respectively. Subsequently, total SV time during the entire week was calculated. Each device-specific SV time was determined in the same way but only including information for respective devices.

Two SV statuses are presented, (1) 'any SV per day', and (2) 'SV $\geq 2 \mathrm{~h}$ /day' on any device, as well as for different screen devices. The second SV status is based on previously cited SV recommendations that indicate that even older children should not engage in more than $2 \mathrm{~h}$ of SV per day. We therefore chose this cut-off to indicate 'heavy' SV exposure.

\section{Independent variables}

Sociodemographic information of the parent was recorded, including ethnicity, parents' education, 
parental marital status and household income, together with the child's age and gender. The screen environment at home was determined by assessing the number of functioning screen devices at home. The number of screen devices was recorded separately for each device type. Parental knowledge of professional SV recommendations for children under the age of 2 years was categorised into three categories: minimise SV altogether, less than $2 \mathrm{~h}$ of SV time, and $\geq 2 \mathrm{~h}$ of SV time. Parental SV was determined and summarised in the same way as for children. Total parental SV time was categorised according to tertiles.

Parental rule setting practices focused on whether parents set rules on the time (duration per day) and the programme (content) of their child's SV, respectively. These variables were combined (parents who set rules on both time and type of programme vs parents who did not set rules on time and programme) because of the strong association between both variables. The exact daily SV time permitted according to parental rules was further assessed and categorised into four groups: 'no SV rules', 'SV time $\geq 2$ h' rule, 'SV time of less than $2 \mathrm{~h}$ ' rule and 'no SV time' rule.

\section{Data analysis}

For categorical variables, counts and percentages were reported while for continuous variables, the median and interquartile ranges (IQRs) were reported. To assess association between categorical variables, the $\chi^{2}$ or Fisher exact tests were used where appropriate. The Kruskal-Wallis test was used to assess association between continuous and categorical variables. Multiple logistic regression was used to model two representations of SV status, 'any SV per day' and 'SV of $\geq 2 \mathrm{~h} /$ day' (representing 'heavy users'), where sociodemographic factors, parental knowledge and practices were the independent variables. In these analyses, both rule setting characteristics (time and programme) were combined as 'parents that set rules on time and type of programme'. To further explore the association with specific types of rules and the strictness of rules on time (with regard to the permitted duration of SV per day), multiple logistic regression analysis was performed separately for 'rules on time', 'rules on programme' and the strictness of rules on time in terms of the permitted SV time. The $\mathrm{OR}$, its $95 \% \mathrm{CI}$ and $\mathrm{p}$ values were reported. A $\mathrm{p}$ value $<0.05$ was considered statistically significant. The statistical analysis was carried out using the IBM Statistical Package for Social Sciences and Stata V.12.

\section{RESULTS}

\section{Study population}

All 1061 parent-child dyads visiting the assessment sites during the assessment periods were approached. Of them, 794 met the inclusion criteria and 725 (91.3\%) provided consent, participated in the survey and provided complete information on the outcome variables of SV time.

Child and parental characteristics of the study population are presented in table 1. Findings show that $55.3 \%$ of children were male and the majority $(58.6 \%)$ were of Chinese ethnicity with the remainder being mostly of Malay or Indian ethnicity. The median age of the children was 7 (IQR 10) months with $44.7 \%$ being younger than 6 months and $55.3 \%$ being $6-24$ months old. The majority of parents were married $(98.1 \%)$ where $79.5 \%$ of fathers and $76.0 \%$ of mothers had attained an educational level of postsecondary school and above. The majority of households $(81.1 \%$ ) had a monthly income of SG $\$ 3000$ (where SG\$3000 is approximately US\$2011) or more.

The most common screen devices in households were mobile devices with a median of four devices per household, followed by TVs and computer. Video game consoles were considerably less common. With regard to the knowledge about professional SV recommendations, only $12.7 \%$ of parents were aware that SV in children below the age of 2 should be minimised and almost twice as many parents (26\%) believed that the recommended duration was $2 \mathrm{~h}$ or more per day as recommended by guidelines. About $80 \%$ of parents set rules on time or programme of SV, and about $75 \%$ set rules on both time and programme. Although more than $10 \%$ of parents appeared to know that SV should be minimised according to professional SV recommendations, less than 5\% among parents set rules to minimise SV. More than $75 \%$ of parents with rules on SV time set rules of less than $2 \mathrm{~h}$ SV per day (or 63\% among all 725 parents).

\section{SV behaviour}

The prevalence of daily SV among children is presented in detail in table 2. The overall prevalence of daily SV was $53.5 \%$, with TVs being most widely used (44.8\%), followed by mobile devices $(30.5 \%)$, computers $(6.6 \%)$ and video game consoles $(0.4 \%)$. The prevalence of daily SV of $2 \mathrm{~h}$ or more per day across all devices was $16.3 \%$, and the prevalence of TV, mobile device, computer and video game console viewing was $11.4 \%, 3.9 \%$, $1.0 \%$ and $0.0 \%$, respectively.

Figure 1 presents the prevalence of daily total SV and by device, as well as SV $2 \mathrm{~h}$ or more per day across 6-month age groups. Among children younger than 6 months, any daily SV activity was reported in $29 \%$, and a higher prevalence was reported with increasing age, being $88.2 \%$ at age $18-24$ months. Differences between age groups and SV status across all devices and each device (apart from video consoles) were statistically significant. In all age groups, TV viewing was the most common form of SV behaviour, followed by mobile devices, computers and video game consoles. The difference in prevalence of SV between TV and mobile device was less pronounced at age 18-24 months as compared with the younger age groups. 
Table 1 Participant, child and household characteristics $(n=725)$

\begin{tabular}{|c|c|c|}
\hline & $\mathrm{N}$ per group & Per cent of total \\
\hline \multicolumn{3}{|l|}{ Sociodemographic characteristics } \\
\hline Male & 401 & 55.3 \\
\hline Female & 324 & 44.7 \\
\hline$<6$ months & 324 & 44.7 \\
\hline $6-24$ months & 401 & 55.3 \\
\hline Age in months (median, IQR) & 725 & $7.0(10.0)$ \\
\hline Chinese & 425 & 58.6 \\
\hline Malay & 196 & 27.0 \\
\hline Indian & 82 & 11.3 \\
\hline Other & 22 & 3.0 \\
\hline Parents not married & 14 & 1.9 \\
\hline Parents married & 711 & 98.1 \\
\hline Mother education (primary/secondary) & 174 & 24.0 \\
\hline Mother education (postsecondary and above) & 551 & 76.0 \\
\hline Father education (primary/secondary) & 148 & 20.5 \\
\hline Father education (postsecondary and above) & 575 & 79.5 \\
\hline Income, SG $\$<3000$ & 134 & 18.9 \\
\hline Income, SG\$3000-SG\$6000 & 297 & 41.8 \\
\hline Income, SG\$6001-SG\$9000 & 170 & 23.9 \\
\hline Income, SG\$>9000 & 109 & 15.4 \\
\hline \multicolumn{3}{|l|}{ Screen home environment } \\
\hline Number of TVs (median, IQR) & 725 & $2(1)$ \\
\hline Number of mobile devices (median, IQR) & 725 & 4 (2) \\
\hline Number of computers (median, IQR) & 725 & $2(1)$ \\
\hline Number of video consoles (median, IQR) & 725 & $0(1)$ \\
\hline \multicolumn{3}{|c|}{ Parental knowledge of professional screen viewing recommendations } \\
\hline Recommend minimal viewing & 91 & 12.7 \\
\hline Recommend viewing $<2 \mathrm{~h} /$ day & 439 & 61.3 \\
\hline Recommend viewing $\geq 2 \mathrm{~h} /$ day & 186 & 26.0 \\
\hline \multicolumn{3}{|l|}{ Parental screen viewing practices } \\
\hline Parent screen time, hours/day (median, IQR) & 713 & $8.0(7.7)$ \\
\hline \multicolumn{3}{|l|}{ Parental rule setting practices } \\
\hline Rules on time & 594 & 82.9 \\
\hline Rules on programme content & 583 & 81.4 \\
\hline Rules on time and programme & 539 & 75.2 \\
\hline Rules on time,${ }^{*}$ no screen time & 27 & 4.6 \\
\hline Rules on time ${ }^{*}$ less than $2 \mathrm{~h}$ & 457 & 76.9 \\
\hline Rules on time,${ }^{*} \geq 2 \mathrm{~h}$ & 110 & 18.5 \\
\hline
\end{tabular}

In those with any SV activity (table 3), median total SV was 60.0 (IQR 95.7) minutes per day among children aged less than 6 months. It was 80 (IQR 120) minutes per day in those aged 18-24 months $(p=0.0004)$. SV aggregated across devices was significantly higher at an older age $(p=0.0004)$, but when investigating different devices a statistically significant difference was only observed for mobile devices.

Table 2 Total and device-specific screen viewing $(n=725)$

\begin{tabular}{|c|c|c|c|c|c|c|}
\hline & \multicolumn{2}{|c|}{ No screen viewing } & \multicolumn{2}{|c|}{$\begin{array}{l}\text { Up to } 2 \mathrm{~h} \text { of screen } \\
\text { viewing }\end{array}$} & \multicolumn{2}{|c|}{$\begin{array}{l}\geq 2 \mathrm{~h} \text { of screen } \\
\text { viewing }\end{array}$} \\
\hline & $\mathbf{N}$ & Per cent & $\mathbf{N}$ & Per cent & $\mathbf{N}$ & Per cent \\
\hline Total screen time & 337 & 46.5 & 270 & 37.2 & 118 & 16.3 \\
\hline TV & 400 & 55.2 & 242 & 33.4 & 83 & 11.4 \\
\hline Mobile device & 504 & 69.5 & 193 & 26.6 & 28 & 3.9 \\
\hline Computer & 677 & 93.4 & 41 & 5.7 & 7 & 1.0 \\
\hline Video game console & 722 & 99.6 & 3 & 0.4 & 0 & 0.0 \\
\hline
\end{tabular}




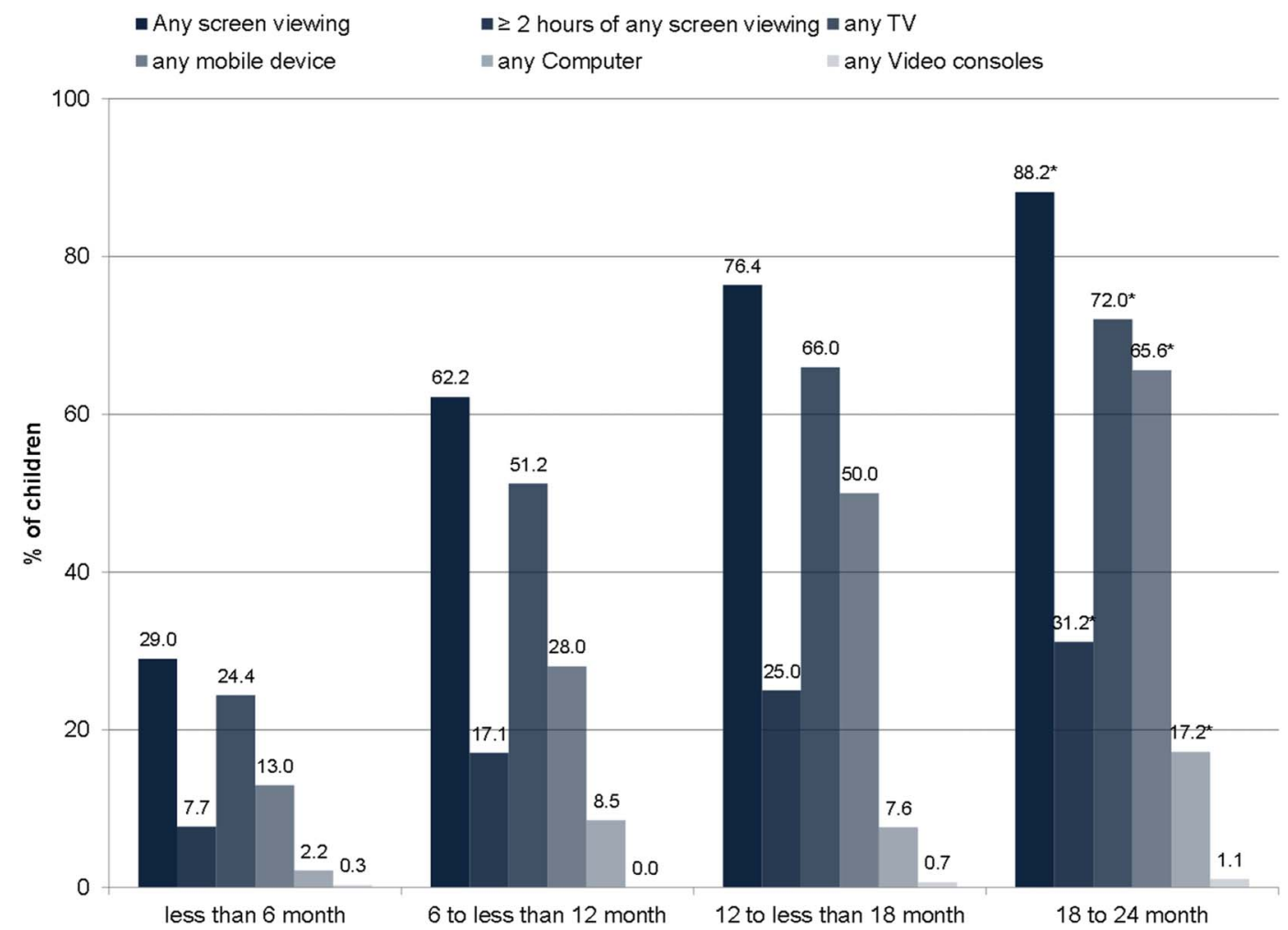

Figure 1 Prevalence of screen viewing behaviour overall and according to device type according to 6-month age groups $(n=725) .{ }^{*}$ Difference across age groups, $p<0.001$.

Sociodemographic, screen home environmental, parental knowledge and practice correlates of SV in children

In unadjusted analysis, increased child age, Malay and Indian ethnicity and lower maternal educational level were significantly associated with higher prevalence of any daily SV behaviour among the sociodemographic variables (table 4). The screen home environment was not significantly associated with SV behaviour and a borderline significant association between lack of parental knowledge of professional SV recommendations and higher prevalence of any daily SV behaviour was found. With regard to practices, parental SV was not significantly associated with daily SV behaviour, but the absence of rule setting practices were significantly associated with higher prevalence of any SV activity among children.

When controlling for all other variables, older children (OR 8.07, 95\% CI 5.57 to 11.69), and children with Malay (OR 2.72, 95\% CI 1.73 to 4.28), Indian (OR 2.53, 95\% CI 1.39 to 4.61 ) or other ethnicities (OR 3.19, $95 \%$ CI 1.13 to 9.05 ) had a significantly increased odds of daily SV. Among home environmental variables, parents who reported having two TVs were significantly more likely to report SV in their children (OR 1.57, 95\% CI 1.03 to 2.40). Although the association between knowledge of SV recommendations and children engaging in any SV was insignificant, parents who believed that guidelines recommend more than $2 \mathrm{~h}$ of $\mathrm{SV}$ had a significant greater odds of engaging in any SV
(OR $1.84,95 \%$ CI 1.00 to 3.39 ). Similarly, children of parents who specified screen time rules had a significant reduced odds of any SV activity (OR $0.65,95 \%$ CI 0.43 to 0.98 ).

As presented in table 5, observed associations with regard to 2 or more hours of SV per day were similar for sociodemographic variables. However, associations with parental knowledge, parental SV and parental rule setting were more consistently and more strongly associated with viewing 2 or more hours per day as compared with any daily SV. The screen home environment had devices with significant associations in the unadjusted analysis. Specifically, a greater number of TVs, mobile devices and video game consoles was significantly associated with higher prevalence of SV time of 2 or more hours. However, they become insignificant in the adjusted analysis. Different from table 4, incorrect parental belief on SV recommendations and higher parental SV time were significantly associated with higher prevalence of SV time of 2 or more hours. Moreover, rule setting practices were significantly associated with lower SV. These significant findings persisted after adjustment.

\section{Association of rule setting type and strictness with SV}

Table 6 presents unadjusted and adjusted associations of rule setting practices with any $\mathrm{SV}$ and $\mathrm{SV}$ of $\geq 2 \mathrm{~h} /$ day. Regardless of the SV outcome and adjustment, 'rules on programme' were not significantly associated with SV in 
young children. On the contrary, 'rules on time' were consistently associated with a lower likelihood of any SV and SV of $\geq 2 \mathrm{~h} /$ day. Moreover, stricter rules on SV time were consistently associated with lower levels of any SV and $\mathrm{SV}$ of $\geq 2 \mathrm{~h} /$ day.

\section{DISCUSSION}

This study investigated SV patterns and their correlates in very young children, considering multiple different screen device types, including TV, computer, as well as mobile screen devices and video game consoles. Given the widespread use, especially of mobile screen devices in day-to-day life, this comprehensive approach is important to fully understand SV patterns. Based on a recent systematic review of the literature, this study is the first in young children to investigate SV patterns and their correlates in such detail. ${ }^{31}$

Our findings show that among children up to the age of 2, SV on a daily basis is very common. Even in children aged less than 6 months, about $30 \%$ were engaging daily in SV and by the age of 18-24 months, about $90 \%$ of children engaged in daily SV activities. We made similar observations with regard to SV time, so that by the age of 18-24 months the median SV time was almost $1.5 \mathrm{~h} /$ day and almost $1 / 3$ of the children were engaging in 2 or more hours of SV time per day. Our findings are consistent with research from other countries that have previously reported high exposure to $\mathrm{TV}$, computer and videos at young ages. ${ }^{22}$

Although TVs still appear to be the most common form of screen devices young children are exposed to, our findings also highlight that TVs are not the only relevant screen device children are using. Mobile devices have become widely available in the entire population and they now seem to reflect the second most important source of SV in very young children. Furthermore, we noted that the difference in the prevalence between TV and mobile devices is least pronounced at the age of 18-24 months when compared with younger age groups making SV attributable to mobile devices comparable with that with TVs. Moreover, in terms of the SV time, we noted a significant difference across age groups for total SV and mobile devices but not for TVs or other screen devices. Previous studies from the USA and Europe, targeting older children, have also reported on the frequent use of mobile devices. In addition, recent discussions in the scientific literature have addressed the potential health implications of the widespread use of modern mobile screen devices in very young children, but our study appears to be among the first to comprehensively quantify patterns and relevant correlates in this population. ${ }^{27} 2930$

Besides age, we noted that Malay, Indian and other ethnic groups were considerably more likely to engage in any SV and 2 or more hours of SV per day as compared with Chinese. This is consistent with existing literature that also reported ethnic differences in SV in 
Table 4 Unadjusted and adjusted associations between any screen viewing (SV) activity and sociodemographic, home environment, parental knowledge and practices

\begin{tabular}{|c|c|c|c|c|c|c|c|c|c|c|}
\hline & \multirow[b]{2}{*}{$\mathbf{N}$} & \multirow[b]{2}{*}{ Per cent SV } & \multicolumn{4}{|c|}{ Unadjusted model } & \multicolumn{4}{|c|}{ Multivariable model ${ }^{\star}$} \\
\hline & & & OR & $\begin{array}{l}\text { Lower } \\
95 \% \mathrm{Cl}\end{array}$ & $\begin{array}{l}\text { Upper } \\
95 \% \mathrm{Cl}\end{array}$ & $\mathrm{p}$ Value & $\mathbf{O R}^{*}$ & $\begin{array}{l}\text { Lower } \\
\mathbf{9 5 \%} \mathrm{Cl}\end{array}$ & $\begin{array}{l}\text { Upper } \\
95 \% \mathrm{Cl}\end{array}$ & p Value* \\
\hline \multicolumn{11}{|l|}{ Sociodemographic characteristics } \\
\hline Age, $<6$ months & 324 & 29.0 & 1.0 & & & & 1.0 & & & \\
\hline Age, $>6$ months & 401 & 73.3 & 6.72 & 4.85 & 9.32 & $<0.001$ & 8.07 & 5.57 & 11.69 & $<0.001$ \\
\hline Chinese & 425 & 46.6 & 1.0 & & & $<0.001 \dagger$ & 1.0 & & & $<0.001 \dagger$ \\
\hline Malay & 196 & 65.3 & 2.16 & 1.52 & 3.06 & $<0.001$ & 2.72 & 1.73 & 4.28 & $<0.001$ \\
\hline Indian & 82 & 58.5 & 1.62 & 1.00 & 2.61 & 0.049 & 2.53 & 1.39 & 4.61 & 0.002 \\
\hline Others & 22 & 63.6 & 2.01 & 0.82 & 4.88 & 0.125 & 3.19 & 1.13 & 9.05 & 0.029 \\
\hline Male & 401 & 55.1 & 1.0 & & & & 1.0 & & & \\
\hline Female & 324 & 51.5 & 0.87 & 0.65 & 1.16 & 0.338 & 0.93 & 0.65 & 1.32 & 0.686 \\
\hline Mother education (primary/secondary) & 174 & 60.9 & 1.0 & & & & 1.0 & & & \\
\hline Mother education (postsecondary) & 551 & 51.2 & 0.67 & 0.48 & 0.95 & 0.025 & 0.70 & 0.42 & 1.16 & 0.167 \\
\hline Father education (primary/secondary) & 148 & 59.5 & 1.0 & & & & 1.0 & & & \\
\hline Father education (postsecondary) & 575 & 51.8 & 0.73 & 0.51 & 1.06 & 0.098 & 1.00 & 0.60 & 1.66 & 0.993 \\
\hline Income, $<3000$ & 134 & 58.2 & 1.0 & & & $0.278 \dagger$ & 1.0 & & & $0.929 \dagger$ \\
\hline Income, 3000-6000 & 297 & 54.2 & 0.85 & 0.56 & 1.28 & 0.439 & 0.96 & 0.57 & 1.62 & 0.882 \\
\hline Income, 6001-9000 & 170 & 52.4 & 0.79 & 0.50 & 1.25 & 0.309 & 1.11 & 0.59 & 2.08 & 0.755 \\
\hline Income, $>9000$ & 109 & 45.9 & 0.61 & 0.37 & 1.01 & 0.056 & 0.94 & 0.47 & 1.90 & 0.866 \\
\hline Parents married & 711 & 53.3 & 1.0 & & & & 1.0 & & & \\
\hline Parents not married & 14 & 64.3 & 1.58 & 0.52 & 4.75 & 0.418 & 1.85 & 0.52 & 6.62 & 0.343 \\
\hline \multicolumn{11}{|l|}{ Screen home environment } \\
\hline Up to $1 \mathrm{TV}$ & 309 & 49.5 & 1.0 & & & $0.176 \dagger$ & 1.0 & & & $0.111 \dagger$ \\
\hline $2 \mathrm{TVs}$ & 236 & 56.8 & 1.34 & 0.95 & 1.88 & 0.093 & 1.57 & 1.03 & 2.40 & 0.036 \\
\hline $3+\mathrm{TVs}$ & 180 & 56.1 & 1.30 & 0.90 & 1.89 & 0.159 & 1.29 & 0.79 & 2.10 & 0.315 \\
\hline Up to 2 mobile devices & 157 & 47.8 & 1.0 & & & $0.265 \dagger$ & 1.0 & & & $0.326 \dagger$ \\
\hline 3 Mobile devices & 199 & 55.3 & 1.35 & 0.89 & 2.06 & 0.160 & 1.47 & 0.89 & 2.45 & 0.135 \\
\hline 4+ Mobile devices & 369 & 55.0 & 1.34 & 0.92 & 1.94 & 0.128 & 1.26 & 0.77 & 2.07 & 0.352 \\
\hline Up to 1 computer & 312 & 58.3 & 1.0 & & & $0.078 \dagger$ & 1.0 & & & $0.892 \dagger$ \\
\hline 2 Computers & 242 & 49.8 & 0.71 & 0.51 & 0.99 & 0.046 & 1.10 & 0.72 & 1.70 & 0.656 \\
\hline 3+ Computers & 171 & 50.0 & 0.71 & 0.49 & 1.04 & 0.078 & 1.02 & 0.61 & 1.70 & 0.939 \\
\hline 0 Video consoles & 504 & 53.0 & 1.0 & & & & 1.0 & & & \\
\hline 1+ Video consoles & 221 & 54.8 & 1.07 & 0.78 & 1.48 & 0.659 & 1.04 & 0.69 & 1.56 & 0.863 \\
\hline \multicolumn{11}{|c|}{ Parental knowledge of professional recommendations } \\
\hline Recommend minimal viewing & 91 & 41.8 & 1.0 & & & $0.058 \dagger$ & 1.0 & & & $0.145 \dagger$ \\
\hline Recommend viewing $<2 \mathrm{~h} /$ day & 439 & 55.1 & 1.71 & 1.08 & 2.71 & 0.021 & 1.45 & 0.85 & 2.46 & 0.172 \\
\hline Recommend viewing $>2 \mathrm{~h} /$ day & 186 & 55.4 & 1.73 & 1.04 & 2.87 & 0.034 & 1.84 & 1.00 & 3.39 & 0.049 \\
\hline \multicolumn{11}{|l|}{ Parental SV practices } \\
\hline Parent screen time (lowest tertile) & 238 & 55.9 & 1.0 & & & $0.357 \dagger$ & 1.0 & & & $0.430 \dagger$ \\
\hline & & & & & & & & & & Continued \\
\hline
\end{tabular}




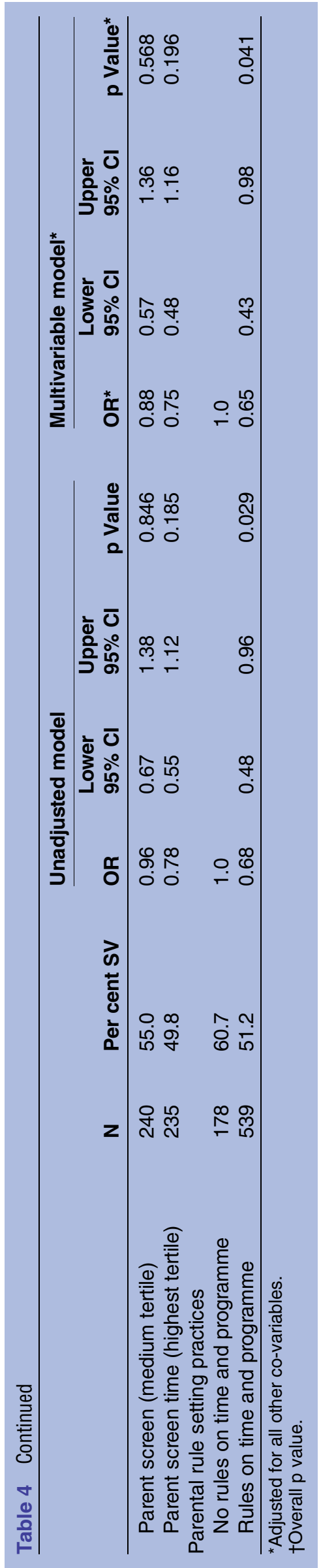

Western populations. ${ }^{31}{ }^{34}$ On the other hand, we did not identify significant associations between daily SV or SV of 2 or more hours per day and other sociodemographic variables, such as child's gender, mother's or father's educational level, income and parental marital status, when taking potential confounders into consideration. ${ }^{31}$

Parental knowledge and parenting practices may have the potential to reflect targets for health promotion strategies to reduce or delay the update of SV in very young children. Our study found strong and consistent associations between child SV and parental rule setting practices. Findings indicate that children are less likely to engage in SV if parents set rules on SV time, and additionally if the rules on SV time are stricter. On the other hand, rules on programmes did not appear to be significantly associated with SV in children. A recent systematic review of the literature reported mixed and less consistent findings of such TV policies at home. However, this review summarised studies of very different methodology and, importantly, mostly targeted older children and adolescents. Only two of the included studies had focused on children below the age of 2, and they only concentrated on TV viewing. ${ }^{35-37}$ Our findings are similar to previous research in older children, however, that also indicated that the type of rules (time or programme) may have implications in terms of $\mathrm{SV}^{37}$ In addition to rule setting practices, knowledge of professional SV recommendations and parental SV behaviour was significantly associated with SV in children, particularly with viewing 2 or more hours per day. These findings seem to be consistent with studies conducted in older children and adolescents that reported associations between children's and parental SV. ${ }^{27} 3138$

Our study has a number of strengths, including a very high participation rate and detailed outcome assessments. Building on Singapore's National Childhood Immunization programme facilitated this study of a defined population of healthy children aged 2 and below. Some limitations, however, have to be acknowledged. First, the survey recruited from 2 out of the 18 polyclinics covering the whole of Singapore. Variations in the overall population reflected in the other centres may hence be unaccounted for. Second, this is a crosssectional study which limits its ability to draw inferences about the direction of cause and effect. However, modern screen devices, in particular tablets, have only become widely used after the launch of the iPad in 2010. Hence, at this stage, longitudinal data on the use and determinants of modern screen devices are not available. Third, the study was conducted in February and may not reflect seasonal variations in screen time exposure, although seasonal variation in weather is limited in tropical Singapore. Fourth, our study relied on a proxy report. While questionnaires were developed on the basis of the existing literature and extensively piloted, they were not validated and we were not able to determine SV objectively. This could introduce measurement bias. Finally, we did not distinguish between the type 
Table 5 Unadjusted and adjusted associations between screen viewing (SV) time per day $\geq 2 \mathrm{~h}$ and sociodemographic, home environment, parental knowledge and practices

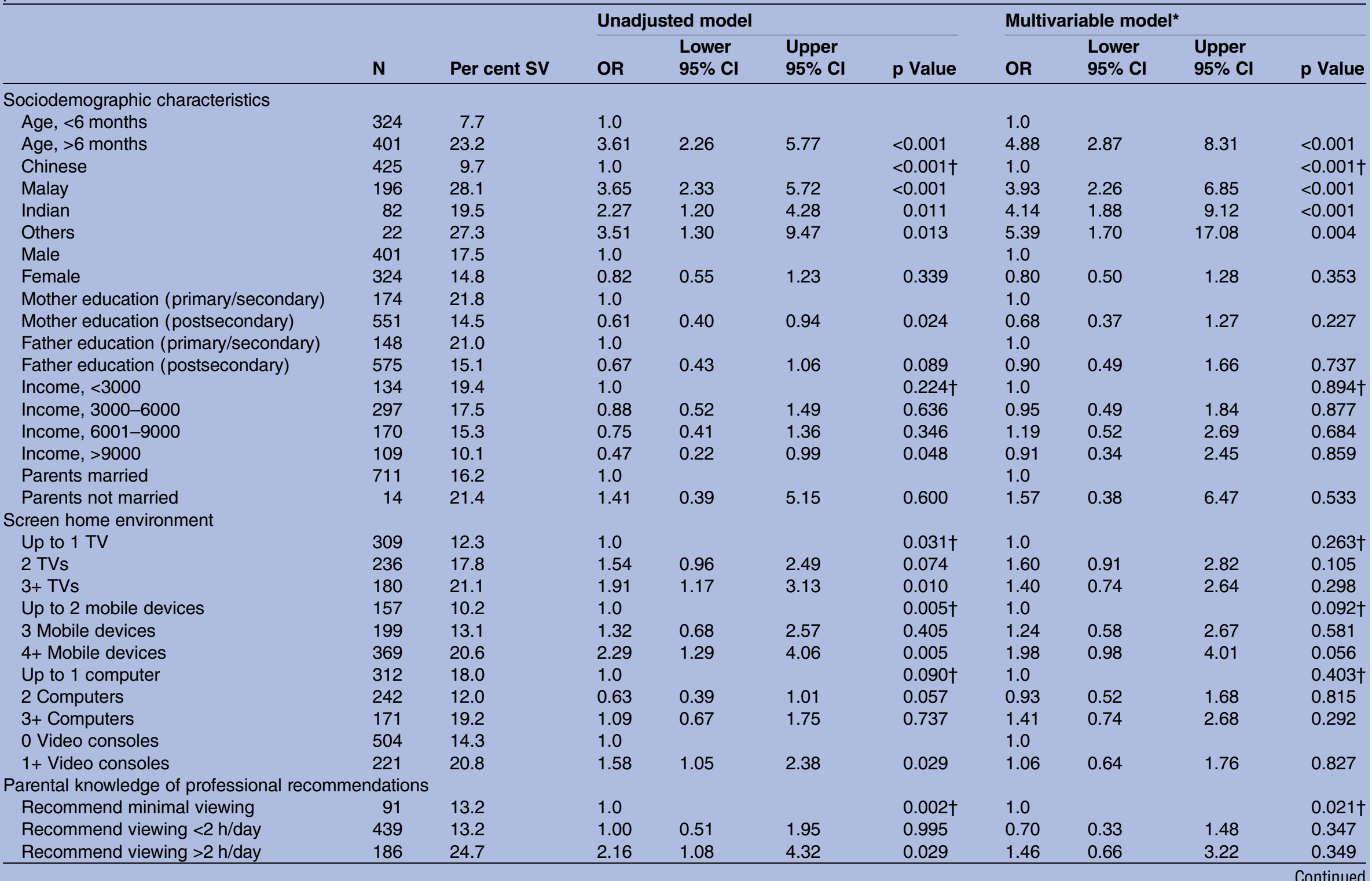


Table 5 Continued

\begin{tabular}{|c|c|c|c|c|c|c|c|c|c|c|}
\hline & \multirow[b]{2}{*}{$\mathbf{N}$} & \multirow[b]{2}{*}{ Per cent SV } & \multicolumn{4}{|c|}{ Unadjusted model } & \multicolumn{4}{|c|}{ Multivariable model ${ }^{*}$} \\
\hline & & & OR & $\begin{array}{l}\text { Lower } \\
95 \% \mathrm{Cl}\end{array}$ & $\begin{array}{l}\text { Upper } \\
95 \% \mathrm{Cl}\end{array}$ & $\mathrm{p}$ Value & OR & $\begin{array}{l}\text { Lower } \\
95 \% \mathrm{Cl}\end{array}$ & $\begin{array}{l}\text { Upper } \\
95 \% \text { Cl }\end{array}$ & p Value \\
\hline \multicolumn{11}{|l|}{ Parental SV practices } \\
\hline Parent SV time (highest tertile) & 235 & 23.0 & 1.99 & 1.23 & 3.23 & 0.005 & 1.90 & 1.07 & 3.36 & 0.028 \\
\hline \multicolumn{11}{|l|}{ Parental rule setting practices } \\
\hline No rules on time and programme & 178 & 21.9 & 1.0 & & & & 1.0 & & & \\
\hline
\end{tabular}

${ }^{*}$ Adjusted for all other co-variables.

tOverall $p$ value.

Table 6 Unadjusted and adjusted associations of types of rules and strictness of rules with any screen viewing and $\geq 2 \mathrm{~h}$ of screen viewing

\begin{tabular}{|c|c|c|c|c|c|c|c|c|c|c|c|c|c|c|}
\hline & \multicolumn{7}{|c|}{ Any screen viewing } & \multicolumn{7}{|c|}{$\geq 2 \mathrm{~h}$ of screen viewing } \\
\hline & $\mathbf{N}$ & $\begin{array}{l}\text { Per cent } \\
\text { screen } \\
\text { viewing }\end{array}$ & p Value & OR $^{*}$ & $\begin{array}{l}\text { Lower } \\
95 \% \mathrm{Cl}\end{array}$ & $\begin{array}{l}\text { Upper } \\
95 \% \mathrm{Cl}\end{array}$ & p Value* & $\mathbf{N}$ & $\begin{array}{l}\text { Per cent } \\
\text { screen } \\
\text { viewing }\end{array}$ & p Value & OR $^{*}$ & $\begin{array}{l}\text { Lower } \\
95 \% \mathrm{Cl}\end{array}$ & $\begin{array}{l}\text { Upper } \\
95 \% \mathrm{Cl}\end{array}$ & p Value* \\
\hline \multicolumn{15}{|l|}{ Rules on programme content } \\
\hline Yes & 583 & 52.3 & & 1.0 & & & & 583 & 16.1 & & 1.0 & & & \\
\hline No & 133 & 58.7 & 0.187 & 1.45 & 0.92 & 2.28 & 0.111 & 133 & 15.8 & 0.925 & 1.11 & 0.62 & 1.98 & 0.730 \\
\hline \multicolumn{15}{|l|}{ Rules on time } \\
\hline Yes & 594 & 50.8 & & 1.0 & & & & 594 & 13.8 & & 1.0 & & & \\
\hline No & 123 & 66.7 & 0.001 & 1.72 & 1.07 & 2.78 & 0.026 & 123 & 27.6 & $<0.001$ & 2.33 & 1.37 & 3.98 & 0.002 \\
\hline Strictness of rules on time & & & $<0.001 \dagger$ & & & & $0.003 \dagger$ & & & $<0.001 \dagger$ & & & & $<0.001 \dagger$ \\
\hline No rules on time & 123 & 66.7 & & 1.0 & & & & 123 & 27.6 & & 1.0 & & & \\
\hline $\mathrm{O} \mathrm{h}$ of screen viewing & 27 & 14.8 & $<0.001$ & 0.09 & 0.02 & 0.36 & 0.001 & $\ddagger$ & & & & & & \\
\hline Less than $2 \mathrm{~h}$ of screen viewing & 457 & 52.5 & 0.005 & 0.65 & 0.40 & 1.07 & 0.091 & $484 \ddagger$ & 10.3 & $<0.001$ & 0.29 & 0.17 & 0.52 & $<0.001$ \\
\hline$\geq 2 \mathrm{~h}$ of screen viewing & 110 & 52.7 & 0.031 & 0.50 & 0.27 & 0.94 & 0.031 & 110 & 31.8 & 0.486 & 0.98 & 0.51 & 1.89 & 0.955 \\
\hline
\end{tabular}

${ }^{*}$ Adjusted for age, gender, ethnicity, mother's education, father's education, parental marital status, income, number of TVs, number of mobile devices, number of computers, number of video

game consoles, knowledge of screen viewing recommendations, parental screen viewing.

tOverall $p$ value.

$\neq$ Combined categories due to $n=0$ screen viewing in rule category ' 0 screen viewing'. 
of programme screen time was spent on or whether it was, for instance, spent for video calling with family members. This will be important to consider in future studies because research has indicated that health consequences may vary depending on the activity performed. ${ }^{39}$

Our findings have considerable public health implications because they highlight the importance of targeting SV practices at a very early age, ideally even during the first 6 months of life in order to develop appropriate practices to prevent the update of these activities in the first place. Our study also showed that TV viewing still seems to be the most common but not the only relevant screen device young children are exposed to. With increasing age, mobile devices take up an increasing part of total SV time, and by the age of 18-24 months are almost as prevalent as TVs. Different devices may require different intervention strategies and recommendations, given their portability, small size and multifunctional usability (eg, watching videos, playing games, reading, listening to audiobooks). We were able to identify a number of potentially modifiable factors that were strongly associated with SV practices in children, including parental knowledge of professional SV recommendations, parental SV and rule setting practices and, to a lesser degree, the number of devices in the household. These findings were particularly present in the case of heavy SV, which suggests that reducing SV behaviour in young children might be an achievable target, while replacing SV entirely could be more challenging. Modifiable factors offer opportunities for health promotion strategies, administered for instance by healthcare professionals during developmental assessments or teachers in childcare centres at a very young age. This could help to delay and reduce SV in children. Our findings are consistent with earlier publications that reported a high prevalence of regular TV viewing in very young children. ${ }^{19} 202240$ However, our findings expand the existing literature considerably in various aspects. Importantly, we were able to investigate multiple up-to-date screen device types and a broad spectrum of sociodemographic, environmental, parental knowledge and practices related correlates of SV in very young children. In addition, literature reviews have shown that the bulk of the existing evidence comes from the USA and Europe, with a very limited number of studies from Asian countries, despite the rapid economic development and increasing concerns about the increase in non-communicable diseases. ${ }^{31}$

In conclusion, our study found a high prevalence of SV overall. Within the first 2 years of a child's life, the prevalence of SV increased across age groups. By the age of 2 years, almost all children were exposed to screen devices daily and a substantial proportion of this young study population exceeded $2 \mathrm{~h}$ of SV, usually recommended as the maximum for much older children. While TV viewing remains the most common contributor to overall SV in children, our findings also confirm the increasingly important role of mobile screen devices. Strategies aimed at reducing the rapid uptake of regular SV practices in children are urgently needed to influence future behaviours and health. We were able to identify potential targets for such strategies, especially for SV or 2 or more hours per day, including parental knowledge regarding professional SV recommendations, parental SV practices and the implementation of strict rules on SV time in young children.

\section{Author affiliations}

${ }^{1}$ Yong Loo Lin School of Medicine, National University of Singapore and National University Health System, Singapore

${ }^{2}$ Saw Swee Hock School of Public Health, National University of Singapore and National University Health System, Singapore

${ }^{3}$ Department of Nutrition, Harvard School of Public Health, Boston, Massachusetts, USA

${ }^{4}$ National Healthcare Group Polyclinics, Singapore

${ }^{5}$ Institute for Social Medicine, Epidemiology and Health Economics, Charite Univeristy Medical Centre Berlin, Berlin, Germany

Acknowledgements The authors acknowledge the contribution of all members of the iBaby Community Health Project group (Yong Loo Lin School of Medicine, National University of Singapore) who supported the data collection and conduct of this study. They further acknowledge the National Healthcare Group for the support in data collection at Polyclinics.

Contributors SNG, LHT, WRT and SA conceptualised and carried out the study and contributed towards the drafting of the manuscript. FM-R contributed towards the conceptualisation of the study, performed the statistical analysis, and drafted the manuscript. All other authors contributed towards the conceptualisation of the study and critically revised the manuscript. All authors read and approved the final manuscript.

Funding This research received no specific grant from any funding agency in the public, commercial or not-for-profit sectors.

\section{Competing interests None declared.}

Ethics approval National Health Care Group, Domain Specific Review Board.

Provenance and peer review Not commissioned; externally peer reviewed.

Data sharing statement No additional data are available.

Open Access This is an Open Access article distributed in accordance with the Creative Commons Attribution Non Commercial (CC BY-NC 4.0) license, which permits others to distribute, remix, adapt, build upon this work noncommercially, and license their derivative works on different terms, provided the original work is properly cited and the use is non-commercial. See: http:// creativecommons.org/licenses/by-nc/4.0/

\section{REFERENCES}

1. Hu FB, Li TY, Colditz GA, et al. Television watching and other sedentary behaviors in relation to risk of obesity and type 2 diabetes mellitus in women. JAMA 2003;289:1785-91.

2. Grøntved A, Hu FB. Television viewing and risk of type 2 diabetes, cardiovascular disease, and all-cause mortality: a meta-analysis. JAMA 2011;305:2448-55.

3. Chonchaiya W, Pruksananonda C. Television viewing associates with delayed language development. Acta Paediatr 2008;97:977-82.

4. Zimmerman FJ, Christakis DA, Meltzoff AN. Associations between media viewing and language development in children under age 2 years. J Pediatr 2007;151:364-8.

5. Kirkorian HL, Pempek TA, Murphy LA, et al. The impact of background television on parent-child interaction. Child Dev 2009;80:1350-9.

6. Mendelsohn AL, Brockmeyer CA, Dreyer BP, et al. Do Verbal Interactions with Infants During Electronic Media Exposure Mitigate Adverse Impacts on their Language Development as Toddlers? Infant Child Dev 2010;19:577-93.

7. Christakis DA, Zimmerman FJ, DiGiuseppe DL, et al. Early television exposure and subsequent attentional problems in children. Pediatrics 2004;113:708-13. 
8. Verlinden $\mathrm{M}$, Tiemeier $\mathrm{H}$, Hudziak JJ, et al. Television viewing and externalizing problems in preschool children: the Generation $\mathrm{R}$ Study. Arch Pediatr Adolesc Med 2012;166:919-25.

9. Comstock G, Strasburger VC. Deceptive appearances: television violence and aggressive behavior. $J$ Adolesc Health Care 1990;11:31-44.

10. Singer MI, Slovak K, Frierson T, et al. Viewing preferences, symptoms of psychological trauma, and violent behaviors among children who watch television. J Am Acad Child Adolesc Psychiatry 1998;37:1041-8.

11. Johnson JG, Cohen P, Smailes EM, et al. Television viewing and aggressive behavior during adolescence and adulthood. Science 2002;295:2468-71.

12. Mendoza JA, Zimmerman FJ, Christakis DA. Television viewing, computer use, obesity, and adiposity in US preschool children. Int $J$ Behav Nutr Phys Act 2007;4:44.

13. Yingyong $P$. Risk factors for refractive errors in primary school children (6-12 years old) in Nakhon Pathom Province. J Med Assoc Thai 2010;93:1288-93.

14. Czepita D, Mojsa A, Ustianowska M, et al. Reading, writing, working on a computer or watching television, and myopia. Klin Oczna 2010;112:293-5.

15. Ekelund U, Brage S, Froberg $\mathrm{K}$, et al. TV viewing and physical activity are independently associated with metabolic risk in children: the European Youth Heart Study. PLoS Med 2006; 3:e488.

16. Communications Co, Media. Children, adolescents, and the media. Pediatrics 2013;132:958-61.

17. Communications Co, Media. Media use by children younger than 2 years. Pediatrics 2011;128:1040-5.

18. Tremblay MS, Leblanc AG, Carson V, et al, Canadian Society for Exercise Physiology. Canadian Sedentary Behaviour Guidelines for the early years (aged 0-4 years). Appl Physiol Nutr Metab 2012;37:370-91.

19. Cheng S, Maeda T, Yoichi S, et al. Early television exposure and children's behavioral and social outcomes at age 30 months. J Epidemiol 2010;20(Suppl 2):S482-9.

20. Authority ACaM. Children's viewing patterns on commercial, free-to-air and subscription television: report analysing audience and ratings data for 2001, 2005 and 2006. ACMA, 2007.

21. Media CS. Zero to eight children's media use in America. Common Sense Media 2013:1-40.

22. Zimmerman FJ, Christakis DA, Meltzoff AN. Television and dvd/ video viewing in children younger than 2 years. Arch Pediatr Adolesc Med 2007;161:473-9.

23. Janz KF, Burns TL, Levy SM. Tracking of activity and sedentary behaviors in childhood: the lowa Bone Development Study. Am J Prev Med 2005;29:171-8.

24. Hancox RJ, Milne BJ, Poulton R. Association between child and adolescent television viewing and adult health: a longitudinal birth cohort study. Lancet 2004;364:257-62.
25. Christakis DA, Zimmerman FJ. Early television viewing is associated with protesting turning off the television at age 6. Med Gen Med 2006;8:63

26. Smith L, Gardner B, Hamer M. Childhood correlates of adult TV viewing time: a 32-year follow-up of the 1970 British Cohort Study. $J$ Epidemiol Community Health 2015;69:309-13.

27. Jago R, Sebire SJ, Edwards MJ, et al. Parental TV viewing, parental self-efficacy, media equipment and TV viewing among preschool children. Eur J Pediatr 2013;172:1543-5.

28. Jiang $X X$, Hardy LL, Ding $D$, et al. Recreational screen-time among Chinese adolescents: a cross-sectional study. J Epidemiol 2014;24:397-403.

29. Radesky JS, Schumacher J, Zuckerman B. Mobile and interactive media use by young children: the good, the bad, and the unknown. Pediatrics 2015;135:1-3.

30. Christakis DA. Interactive media use at younger than the age of 2 years: time to rethink the American Academy of Pediatrics guideline? JAMA Pediatr 2014;168:399-400.

31. Duch H, Fisher E, Ensari I, et al. Screen time use in children under 3 years old: a systematic review of correlates. Int $J$ Behav Nutr Phys Act 2013;10:102.

32. Jayawardena A, Yeong CC, Martin R, et al. Immunisation uptake in Singapore. Singapore Fam Physician 2011;37:31-5.

33. Anderson DR, Field DE, Collins PA, et al. Estimates of young children's time with television: a methodological comparison of parent reports with time-lapse video home observation. Child Dev 1985;56:1345-57

34. Flores G, Tomany-Korman S, Olson L. Does disadvantage start at home? Racial and ethnic disparities in health-related early childhood home routines and safety practices. Arch Pediatr Adolesc Med 2005;159:158-65.

35. Jago R, Edwards MJ, Urbanski CR, et al. General and specific approaches to media parenting: a systematic review of current measures, associations with screen-viewing, and measurement implications. Child Obes 2013;9(Suppl):S51-72.

36. Barr R, Danziger C, Hilliard M, et al. Amount, content and context of infant media exposure: a parental questionnaire and diary analysis. Int J Early Years Educ 2010;18:107-22.

37. Vandewater EA, Park SE, Huang X, et al. "No-you can't watch that": parental rules and young children's media use. Am Behav Sci 2005;48:608-23.

38. Jago R, Thompson JL, Sebire SJ, et al. Cross-sectional associations between the screen-time of parents and young children: differences by parent and child gender and day of the week. Int J Behav Nutr Phys Act 2014:11:54.

39. Roseberry S, Hirsh-Pasek K, Golinkoff RM. Skype me! Socially contingent interactions help toddlers learn language. Child Dev 2014;85:956-70.

40. Certain L, Kahn R. Prevalence, correlates, and trajectory of television viewing among infants and toddlers. Pediatrics 2002;109:634-42 